\title{
Short communication: A food-systems approach to assessing dairy product waste
}

\author{
B. G. Ridoutt, ${ }^{* 1}$ D. L. Baird,† K. Bastiaans, † R. Darnell, † G. A. Hendrie,† M. Riley,† P. Sanguansri,§ \\ J. Syrette,† M. Noakes, $†$ and B. A. Keating\# \\ ${ }^{*}$ CSIRO Animal, Food and Health Sciences, Clayton, Victoria 3169, Australia \\ †CSIRO Animal, Food and Health Sciences, Adelaide, South Australia 5000, Australia \\ $\ddagger C S I R O$ Computational Informatics, Dutton Park, Queensland 4102, Australia \\ $\S C S I R O$ Animal, Food and Health Sciences, Werribee, Victoria 3030, Australia \\ \#CSIRO Sustainable Agriculture National Research Flagship, Dutton Park, Queensland 4102, Australia
}

\begin{abstract}
Concern about world population increase, food security, and the environmental burdens of food production have made food-waste reduction a social and environmental priority. In this context, the quantification of dairy product waste is especially difficult due to the varied means of disposal, by solid and liquid waste streams, and due to inclusion as an ingredient in many processed foods. In this study, food intake data from the Australian National Nutrition Survey $(>13,000$ participants; $>4,500$ food items) were disaggregated into basic foods and total national dairy product intake was expressed in whole-milk equivalents. This result was compared with total domestic milk supply, indicating a level of waste of $29 \%$ for dairy products in the Australian food system. With national food-waste reduction targets becoming increasingly common, reliable estimates of food waste at the national scale are important for goal setting, baseline reporting, and performance monitoring. For this purpose, the systems approach to assessing food waste demonstrated in this project is deemed to have advantages over other common methods of food-waste assessment, such as bin audits, waste diaries, and surveys.
\end{abstract}

Key words: food waste, supply-chain waste, household waste, sustainability

\section{Short Communication}

In the context of world population growth, concerns about food security, and the environmental burdens of food production, food waste has become an issue of high importance (Gustavsson et al., 2011; Gunders, 2012; RSIS, 2012; Bond et al., 2013; IME, 2013). Food

Received February 4, 2014.

Accepted June 16, 2014

${ }^{1}$ Corresponding author: brad.ridoutt@csiro.au waste was the theme of the 2013 World Environment Day organized by the United Nations Environment Programme (Nairobi, Kenya), and the European Parliament designated 2014 as the European Year Against Food Waste. Estimates of food waste differ, according to the definitions used and methods of assessment (Parfitt et al., 2010; Lebersorger and Schneider, 2011). The popular consensus is that between 30 and $50 \%$ of food produced for humans is never eaten. This level of food waste is deemed to be socially and environmentally unacceptable, prompting calls for action across the food chain, including food producers, retailers, and those involved in food purchasing, storage, and preparation (i.e., commercial and household kitchens).

For the dairy sector, food-chain waste is particularly difficult to quantify. This is due to the fluid nature of many of the products and the varied means of disposal. At the kitchen level, wasted dairy products might be disposed of via municipal solid waste. They might also be disposed via the sewer and therefore not included in bin audits. Another factor making quantification of dairy product waste difficult is that the dairy industry supplies consumer products as well as ingredients used in food manufacturing. Dairy products are, therefore, wasted when consumer products such as fluid milk, yogurt, cheese, and ice cream are wasted as well as when ingredients used in food manufacturing are wasted and when consumer products containing dairy ingredients are wasted. Although accurate quantification is not needed to raise general awareness of the issue of food waste, it is important for the development of waste-reduction strategies, for goal setting, and for monitoring the success of waste reduction initiatives. Governmentset targets to reduce food waste are becoming increasingly common. For example, the European Parliament has adopted a resolution to take practical measures toward halving food waste by 2025 (European Parliament, 2012). Australia also has set a goal to reduce per-capita food waste in its National Food Plan (DAFF, 2013). In the future, it will be important for the dairy industry to 
be able to demonstrate quantitative progress in waste reduction to meet stakeholder expectations.

Our research concerns the application of a foodsystems approach to the quantification of food-chain waste, which has the potential to be used for characterizing and monitoring dairy product waste at the scale of a national food system. The purposes of this paper are to present the first comprehensive assessment of dairy product waste in Australia, to make comparison with other available methods, and to explore relevance of the method for dairy sector baseline reporting and performance monitoring.

The general approach to food-waste quantification involved comparison of total national food supply and total national food intake. The difference was attributed to edible and nonedible waste. In the case of dairy products, the farm-gate commodity is whole milk, which is entirely edible, and hence all of the food-system waste was regarded as edible. In this study, no distinction was made between supply-chain losses and waste, as the food system was assessed in its entirety. Some authors differentiate between losses, which are regarded as occurring early in the supply chain, are frequently the result of spoilage, and generally require changes to infrastructure and systems to overcome, and wastage, which is regarded as occurring at the retail and kitchen levels and is more directly related to human behavior and choices. Such distinctions can be important when it comes to the design of specific policies (Parfitt et al., 2010). The food-systems approach adopted in this work differs fundamentally from most other methods of foodwaste quantification, which take a bottom-up approach using bin audits, waste diaries, surveys, expert opinions, and other types of ethnographic study methods.

For this study, data relating to food intake were obtained from the Australian Bureau of Statistics National Nutrition Survey (NNS), which is a periodically repeated comprehensive survey of dietary intake in Australia over all age groups ( $>13,000$ participants aged $2 \mathrm{yr}$ and above) and with nationally representative coverage of urban, rural, and remote communities. The data used were from the 1995 survey (ABS, 1999) because the results of the more recent 2011/2012 survey, due for release in 2014, were not available at the time. Originally adapted from the interview procedure developed by the USDA for the Continuing Survey of Food Intakes by Individuals, the NNS is primarily based on a highly detailed quantitative survey where participants recall and describe all food and beverages and portion sizes eaten during the previous 24 -h period (midnight to midnight). Trained dieticians performed the interviews to maximize data quality, although it is noted that this cannot eliminate all errors associated with the participants' reporting of intake. The survey was conducted over 12 mo to capture variation in eating patterns according to season, and included all days of the week. The main purpose of the NNS is to obtain a generalizable national estimate of nutrient intake and comparison between age, gender, and geographical groups. Based on the NNS data, studies have been conducted on a wide range of topics, including micronutrient intake, fruit and vegetable intake, sugar intake, the intake of "non-core" foods, and the relationships between food intake patterns, income, education, obesity, and parental body mass index, among others.

Our work involved disaggregating the food intake data (>4,500 food items) into basic foods (21 major vegetables, 28 major fruits, 7 different grains, and so on). This task was straightforward in some cases (e.g., a glass of full-cream milk), but complex in the case of others (e.g., milk chocolate consisting of cocoa, sugar, and milk as major ingredients; a tropical pizza consisting of wheat, oil, tomato, pineapple, cheese, and ham as major ingredients). The categorization was undertaken systematically by a team of 5 individuals with expert knowledge of food recipes and composition. By applying the same survey weights as the NNS, the 1995 national intake of basic foods was estimated. Where relevant, conversion factors (predominantly taken from the NUTTAB reference database; FSANZ, 2010) were applied to translate cooked food portions into raw quantities. All dairy products were converted to kilograms of whole-milk equivalents using processing conversion factors (e.g., 1.25 for yogurt to whole milk and 6.67 for cheese to whole milk) and an average density of milk of $1,032 \mathrm{~kg} / \mathrm{m}^{3}$. Care was taken to avoid double counting (e.g., coproducts of reduced-fat milk or cheese making). Food intake for children less than 2 yr old was based on the reported food intake for children of age 2 to $3 \mathrm{yr}$, with adjustment based on relative energy intake.

Data relating to domestic food supply in 1995 were compiled from statistics obtained from the FAOSTAT database (FAO, 2013). This included the Food Balance Sheet for Australia, which is an account of national food supply, taking into account domestic production, imports, exports, stock variations, the utilization of commodities for livestock food supply, and an estimate of post-farm gate supply-chain waste (i.e., excluding harvest and other on-farm losses). Apparent waste was assessed as the difference between national food supply and intake.

Based on analysis of the 1995 NNS, Australia's total national intake (i.e., ingestion) of dairy products was estimated at 3.11 billion kilograms of milk (equivalents). In comparison, for the same year, the total domestic milk supply was an estimated 4.36 billion kilograms, suggesting a level of waste of $29 \%$ for dairy products in the Australian food system (Table 1). Compared 
Table 1. Dairy product waste in the Australian national food system, 1995

\begin{tabular}{lc}
\hline Item & $\begin{array}{c}\mathrm{kg} \text { of milk } \\
\text { equivalent }\left(\times 10^{9}\right)\end{array}$ \\
\hline National intake & 3.11 \\
National supply & 4.36 \\
Domestic production & 8.46 \\
Imports & 0.32 \\
Exports & 4.08 \\
Stock variation & -0.19 \\
Animal feed & 0.14 \\
Apparent waste & 1.25 \\
\hline
\end{tabular}

with most other types of food, quantitative estimates of dairy product waste are relatively uncommon. As mentioned above, this is largely due to the varied means of disposal (solid and liquid waste streams) and the large number of food products incorporating dairy ingredients. The $29 \%$ dairy product waste determined in this study was significantly higher than estimates by the Food and Agriculture Organization of the United Nations (Gustavsson et al., 2011), ranging from 7 to $16 \%$ for the most highly developed world regions comparable to Australia (Table 2). Wastage of purchased milk and yogurt were found to be 7 and $13 \%$, respectively, at the household level in the United Kingdom (WRAP, 2009). This also represents a much lower level of waste than was found in the present study because dairy product waste in the processing, distribution, and retailing stages are reported to be small compared with waste at the kitchen level (Kantor et al., 1997; UNEP, 2000; Gustavsson et al., 2011). In contrast, our result was very similar to the level of dairy product waste reported by the USDA using a material flow analysis based predominantly on loss factors gleaned from published studies and discussions with commodity experts (32\%; Kantor et al., 1997) and with various subsequent refinements (31\%; USDA, 2012; Table 2). Interestingly, the USDA also compared national data on food purchase from retail outlets with data from the US National Health and Nutrition Survey in an effort to further refine food-waste estimates at the household level (Muth et al., 2011). This approach has many similarities to the approach taken in the present study reporting dairy product waste in Australia. In the US case, this process led to many new estimates for food waste at the household level being adopted in the Loss-Adjusted Food Availability (LAFA) Data Series. However, for many dairy products, the revised waste estimates were not adopted, as they were deemed to be unreliable (Muth et al., 2011, page 15).

Reliable estimates of food-chain waste are important. If dairy product waste is on the order of $30 \%$, then the strategic importance of the issue is far higher than if it is less than $10 \%$. Accurate quantification is also essential for performance monitoring and reporting to stakeholders. Clearly, the method chosen to quantify food waste has an important bearing on the results. Rubbish bin audits (e.g., WRAP, 2008) are expensive to conduct and generally do not yield reproducible and comparable data due to the difficulty in classifying mixed and partially degraded waste in a consistent manner (Lebersorger and Schneider, 2011). In addition, they fail to record food waste disposed via the sewer, which is most important for dairy products. Studies using food-waste diaries (e.g., WRAP, 2009) are another means of data collection. However, such studies are typically even more onerous to conduct than bin audits and they are subject to a range of problems related to intentional or unintentional underreporting and the possibility that the process of maintaining a diary influences behavior (Quested et al., 2011). Questionnaires (e.g., Gustavsson and Stage, 2011; BSR, 2013) and ethnographic study methods (e.g., Goonan et al., 2014) have the greatest value in exploring attitudes toward food waste, behaviors that lead to food waste, and barriers to food-waste reduction.

Material flow analyses offer the greater promise as a means of establishing reliable food-waste statistics at the national scale (e.g., Kantor et al., 1997). The issue is whether food waste is the dependent variable in such calculations. Where loss factors, obtained from various sources, are applied to national food supply

Table 2. Comparison of dairy product waste estimates

\begin{tabular}{lcll}
\hline Country/region & $\begin{array}{c}\text { Waste } \\
\text { estimate }(\%)\end{array}$ & Scope & Reference $^{1}$ \\
\hline Europe & 8 & & Gustavsson et al. (2011) \\
North America and Oceania & 16 & Dairy products/food system excluding agriculture & \\
Industrialized Asia & 7 & & WRAP (2009) \\
UK & 7 & Purchased milk/household level & \\
UK & 13 & Purchased yogurt/household level & Kantor et al. (1997) \\
US & 32 & Dairy products/retail, foodservice, and household levels & USDA (2012) \\
US & 31 & Dairy products/retail, foodservice, and household levels & UNEP (2000) \\
Global & $3-4$ & Milk processing &
\end{tabular}

${ }^{1}$ WRAP $=$ Waste \& Resources Action Programme (Banbury, UK); UNEP = United Nations Environment Programme. 
tables, monitoring of loss-adjusted food availability is the outcome, not food-waste performance tracking. To be effective in monitoring changes in food waste, food-supply tables must be compared with food intake. Hall et al. (2009) performed such an analysis, using metabolic energy requirements to estimate food intake, and reported progressive increases in food waste in the United States since 1974. One limitation of this approach is that it reports total food energy wasted and not waste levels for specific food groups or products.

In summary, the methodology presented in this study of food waste in Australia, based on comparison of total national food supply and national intake of basic foods, offers many advantages for baseline reporting and performance monitoring of food waste at the national level, and especially so for the dairy sector. Of course, sources of error exist related to the underlying Food and Agriculture Organization of the United Nations (FAO) food balance sheets and NNS data. For developed country contexts, such as Australia, the accuracy of the FAO food balance sheets is likely to be highest because the majority of agricultural production is traded (Hall et al., 2009). Underreporting is a known feature of national nutrition surveys. However, this problem is more likely to affect reporting of intake of alcoholic beverages, confectionery, and other energyrich, nutrient-poor snack foods rather than mainstream dairy products. The major limitation we recognize is the infrequency at which national nutrition surveys are typically conducted. In this regard, where governments have set food-waste reduction targets, they may also need to reassess the scope and frequency of national survey instruments.

\section{ACKNOWLEDGMENTS}

This project was funded, in part, by the Australian Government Rural Industries Research and Development Corporation (RIRDC, Barton, Australian Capital Territory, Australia; Project No. PRJ-008806). Aspects of the research reported, with the permission of RIRDC, in this paper appear in a report published by RIRDC (Nutritional Sufficiency of the National Food Production System; http://www.rirdc.gov.au/publications).

\section{REFERENCES}

ABS (Australian Bureau of Statistics). 1999. 4804.0-National Nutrition Survey: Foods Eaten, Australia, 1995. ABS, Canberra, Australia.

Bond, M., T. Meacham, R. Bhunnoo, and T. G. Benton. 2013. Food Waste Within Global Food Systems. Biotechnology and Biological Sciences Research Council, Swindon, UK.
BSR. 2013. Analysis of US Food Waste Among Food manufacturers, Retailers, and Wholesalers. Grocery Manufacturers Association, Washington, DC.

DAFF (Department of Agriculture, Fisheries and Forestry). 2013. National Food Plan. DAFF, Canberra, Australia.

European Parliament. 2012. Texts adopted-Thursday 19 January 2012 - Avoiding food wastage. Accessed Jan.14,2014.http://www.eu roparl.europa.eu/sides/getDoc.do?pubRef=-//EP//TEXT+TA+ $\mathrm{P} 7-\mathrm{TA}-2012-0014+0+\mathrm{DOC}+\mathrm{XML}+\mathrm{V} 0 / / \mathrm{EN}$.

FAO (Food and Agriculture Organization of the United Nations). 2013. FAOSTAT. Statistics Division, FAO, Rome, Italy.

FSANZ (Food Standards Australia New Zealand). 2010. NUTTAB 2010 Online Searchable Database. Accessed Oct. 8, 2013. http:// archive.foodstandards.gov.au/consumerinformation/nuttab2010/ nuttab2010onlinesearchabledatabase/onlineversion_code.cfm.

Goonan, S., M. Mirosa, and H. Spence. 2014. Getting the taste for food waste: A mixed methods ethnographic study into hospital food waste before patient consumption conducted at three New Zealand foodservice facilities. J. Acad. Nutr. Diet. 114:63-71.

Gunders, D. 2012. Wasted: How America is Losing Up to 40 Percent of Its Food from Farm to Fork to Landfill. NRDC Issue Paper 12-06B, Natural Resources Defense Council, Washington, DC.

Gustavsson, J., C. Cederberg, and U. Sonesson. 2011. Global Food Losses and Food Waste. Food and Agriculture Organization of the United Nations (FAO), Rome, Italy.

Gustavsson, J., and J. Stage. 2011. Retail waste of horticultural products in Sweden. Resour. Conserv. Recycling 55:554-556.

Hall, K. D., J. Guo, M. Dore, and C. C. Chow. 2009. The progressive increase of food waste in America and its environmental impact. PLoS ONE 4:e7940.

IME (Institution of Mechanical Engineers). 2013. Global Food: Waste Not, Want Not. IME, London, UK.

Kantor, L. S., K. Lipton, A. Manchester, and V. Oliveira. 1997. Estimating and addressing America's food losses. FoodReview 20:212 .

Lebersorger, S., and F. Schneider. 2011. Discussion on the methodology for determining food waste in household waste composition studies. Waste Manag. 31:1924-1933.

Muth, M. K., S. A. Karns, S. J. Nielsen, J. C. Buzby, and H. F. Wells. 2011. Consumer-Level Food Loss Estimates and Their Use in the ERS Loss-Adjusted Food Availability Data. Tech. Bull. 1927. United States Department of Agriculture, Economic Research Service, Washington, DC.

Parfitt, J., M. Barthel, and S. Macnaughton. 2010. Food waste within food supply chains: Quantification and potential for change to 2050. Philos. Trans. R. Soc. Lond. B Biol. Sci. 365:3065-3081.

Quested, T. E., A. D. Parry, S. Easteal, and R. Swannell. 2011. Food and drink waste from households in the UK. Nutr. Bull. 36:460467.

RSIS (S. Rajaratnam School of International Studies). 2012. Expert Working Group Meeting on Food Wastage in Southeast Asia, Report. RSIS Centre for Non-Traditional Security Studies, Nanyang Technological University, Singapore.

UNEP (United Nations Environment Programme). 2000. Cleaner Production Assessment in Dairy Processing. UNEP, Division of Technology, Industry and Economics, Paris, France.

USDA. 2012. Loss-Adjusted Food Availability Documentation. Accessed Dec. 20, 2013. http://www.ers.usda.gov/data-products/foodavailability-\%28per-capita\%29-data-system/loss-adjusted-foodavailability-documentation.aspx.

WRAP (Waste \& Resources Action Programme). 2008. The Food We Waste. WRAP, Banbury, UK.

WRAP (Waste \& Resources Action Programme). 2009. Household Food and Drink Waste in the UK. WRAP, Banbury, UK. 